\title{
Factors Influencing Women Empowerment among Kurumba Tribes in Nilgiris District
}

\author{
D. Kasturi* \\ Research Scholar, Department of History, Government Arts College Udhagamandalam - 643002, Tamil Nadu, \\ India; pssk2012@gmail.com
}

\begin{abstract}
Empowerment of women substantially improves the status of the family and contributes to the growth of the community. In tribal villages there are still places where women are not treated equally to men. As a result, women suffer from poor education, health status and economic growth. Factors such as social, economical, education, political, technology, cultural contributes to empowerment of women. In this paper, factors such as economic, social, demographic and their impact on women empowerment among Kurumba tribes is studied. The better knowledge and understanding of key factors and their role in women development helps to identify women empowerment levels among Kurumba tribes.
\end{abstract}

Keywords: Economical Empowerment, Kurumba Tribes, Social Empowerment, Women Development, Women Empowerment

\section{Introduction}

The development of tribal women contributes to a country's development and it has been accepted all over the world. To improve the status of women, several measures and policies are derived and attempt to improve the social, economical and political status of tribal women. Tribal communities live in forests that are rich in natural resources and add to about $30 \%$ percent to the total population of India. There are various factors that contribute to the under development of tribal women. The role of tribal women in a society defines their status and several factors contribute to their development within the community. Tribal women share an equal contribution to the development of a family as men but the status of tribal women still remains low due to several factors pertaining to health, education, economic, culture, social, political and technology.

In India, tribal welfare programs are given the most importance to improve their social, economical and health status. Since tribal communities suffer from poor education, employment and health owing to their strong cultural values and traditional beliefs which hinder them to adapt to modern culture. The gender inequalities among tribal communities are very high and as a result women suffer greatly than men. Although women equally contribute to the family as men do, a women's contribution is not much recognized and rewarded in the tribal communities. As a result women suffer from poor health, education, and economic condition. Kurumba tribes are the oldest tribes who settled in hills and slopes of Western Ghats. In Kurumba community men are more dominant than women and follow rich tradition and culture where women are restricted to household activities only. In the Kurumba Culture women are given more important than men. With respect to their culture and tradition the status of Kurumba women remain low and as a result women do not have their basic rights such as education, health, ownership, decision making etc. Empowering tribal women helps in building stronger family and communities. When women becomes empowered the quality of men and the family improves. Since cultures and beliefs among tribal communities vary largely, understanding factors that influence women empowerment has become essential to improve the quality of Kurumba women. This study investigates the factors such as economic, social and demographic and their influence on women empowerment among Kurumba tribes in Nilgiris District.

\section{Literature Survey}

Krishnanunni \& Mathews ${ }^{1}$ studied the role of Mahatma Gandhi rural development program in empowering tribal 
women. Tribal women participated in the program gained more job opportunity. The program assured a regular income to the tribal women. The study results indicate that the program empowers tribal women through improvements in their education, poverty, health and income.

Nisha \& Asokhan² studied the factors that affect the tribal women participation in developmental programs. The study was carried in Nilgiris district and involved 120 tribal women. The study found that cultural aspect of the tribal community plays a major role in blocking tribal women participation. Education, lack of awareness and training facilities also affect them.

Mareeswaran et al., , the effect of empowerment through developmental programs. The study involved 200 tribal women and women who participated in the training programs are trained on promoting education, employment, agriculture and health. The training program offered livelihood security to the women participants. At the end of the program tribal women developed independent skills to become entrepreneurs and improved their earning capacities.

Gautam $^{4}$ investigated the impact of SHG in empowering tribal women through skill development. The program was aimed to improve tribal women skills and knowledge. The study findings show that training programs effectively improve the skills and SHG based microfinance schemes improved their social-economic status.

Manjunatha \& Gangadhar ${ }^{\frac{5}{5}}$ studied the socio-economic status of Bettakurba women in Karnataka, India. The study findings reveal that lack of education; patriarchal system and low wages contribute to low economic status. The study suggested agricultural and animal breeding programs could improve their status.

Acharya ${ }^{6}$ studied the impact of SHG entrepreneurial programs on tribes of Odisha district. The study finds out that the impact of SHG based training and development does not bring greater change in the tribal communities. The programs improved their earnings from very low to low category and it helps tribals to improve skills. The study suggested that improving decision making quality, education and health would bring a positive change in their lives.

Mondal $^{7}$ studied the level of empowerment before and after joining SHG among tribal women in West Bengal. The study finds that joining SHG improved tribal women empowerment levels. Factors such as training skills, decision making, and financial gains improved their empowerment levels.

Khanum et al, $\frac{8}{-}$ studied the impact of entrepreneurship improving programs on household income and expenditure of Bangladesh tribal women.
The study finding shows that business and skill development programs have higher degree of impact on income and expenditure as it improves both entrepreneurial income and home income.

Shamna et al., ${ }^{9}$ investigated the factors influencing tribal women in participation in agriculture. The study was carried out in Bangladesh and the tribal women who participated showed better interest on skill developing on farming. Factors such as education, lack of knowledge, child care and low income affected tribal women to participate in agriculture.

\section{Methodology}

\subsection{Objectives}

The main objective of the study is to determine the factors that affect women empowerment among Kurumba tribes in Nilgiris. The main objective is further sub divided into:

- To determine the socio-demographic factors that influence women empowerment among Kurumba tribes.

- To determine the socio-economic factors that influence women empowerment among Kurumba tribes.

\subsection{Research Design}

This study utilizes an explanatory research design using quantitative analysis to find out the factors that affect women empowerment in Kurumba tribes by establishing the relationship between independent and dependent variables. This study use primary data collected through survey instrument prepared for the study. The study was carried out in Nilgiris District involving women Kurumba tribes from a small village with a total population of 240 and a total of 150 samples are selected for the study. The sample size is arrived using method adopted from (Yamane, 1967) and sample size is calculated using the formula,

$$
\text { Sample size }(n)=\frac{N}{1+N(e)^{2}}
$$

Where $\mathrm{N}$ is the population and e is precision at $95 \%$ confidence.

A liner regression model is constructed using independent variables from demographic and socio-economic factors. Women empowerment is the dependent variable $(\mathrm{Y})$ and explanatory factors such as marital status, age, education, income, have electricity, number of years living, send children to school, drop school for job, get aid from government, knowledge on privileges, health programs implemented, place is inherited, self employment, sell 
forest products, difference in wages, SHG useful, discrimination in job, training benefits and forest produce useful as independent variables (X1 ... Xn).

The regression equation is given by:

$$
\mathrm{Y}_{\mathrm{i}}=\mathrm{a}+\mathrm{b}_{1} \mathrm{X}_{1}+\mathrm{b}_{2} \mathrm{X}_{2}+\mathrm{b}_{3} \mathrm{X}_{3}+\mathrm{b}_{4} \mathrm{X}_{4} \ldots \mathrm{b}_{\mathrm{n}} \mathrm{X}_{\mathrm{n}}+\mathrm{e}
$$

where $\mathrm{Yi}$ is the dependent variable, $\mathrm{X}_{1} \ldots \mathrm{X}_{\mathrm{n}}$ is the independent variables, $a$ is the intercept, $b_{1} \ldots b_{n}$ is the slope and $\mathrm{e}$ is the residual error.

\section{Results and Discussion}

Socio-demographic factors that influence women empowerment: To estimate the relationship and to investigate the influence of socio-demographic factors and women empowerment a regression analysis is conducted. The model summary (Table 1 ) shows that the $\mathrm{R}^{2}$ of 0.303 which indicate that the model is explaining about $30 \%$ of variance and the model is significant in measuring the impact of dependent variables with $f$ value of 5.465 and $p$ value less than 0.05 (Table 2). The regression estimates measure the rate of change of one unit in independent variable to one unit of change in dependent value. The social demographic factor such as income $(b=0.350, p=0.008)$, house type $(b=0.575, p=0.015)$, house ownership $(b=0.320$, $\mathrm{p}=0.015)$ and having electricity $(\mathrm{b}=1.033, \mathrm{p}=0.00)$ has a significant relationship with the dependent variable women empowerment while age, marital status, education, family type and marital status does not have a significant relationship with dependent variable. Factor length of stay $(b=-0.435, p=0.017)$ has significant negative relationship with women empowerment meaning that an increase in length of stay leads to decrease in women empowerment.

Table 1. Model summary-socio-demographic

\begin{tabular}{|c|c|c|c|c|}
\hline \multicolumn{5}{|c|}{ Model Summary } \\
\hline Model & $\mathrm{R}$ & R Square & $\begin{array}{c}\text { Adjusted R } \\
\text { Square }\end{array}$ & $\begin{array}{c}\text { Std. Error of the } \\
\text { Estimate }\end{array}$ \\
\hline 1 & .551 & .303 & .248 & .987 \\
\hline
\end{tabular}

Table 2. ANOVA - socio-demographic

\begin{tabular}{|l|l|c|c|c|c|c|}
\hline \multicolumn{7}{|l|}{ ANOVA } \\
\hline \multicolumn{2}{|l|}{ Model } & $\begin{array}{c}\text { Sum of } \\
\text { Squares }\end{array}$ & df & $\begin{array}{c}\text { Mean } \\
\text { Square }\end{array}$ & F & Sig. \\
\hline \multirow{4}{*}{1} & Regression & 58.593 & 10 & 5.327 & 5.465 & .000 \\
& Residual & 134.501 & 138 & .975 & A. & $B$. \\
& Total & 193.093 & 149 & $C$. & D. & E. \\
\hline
\end{tabular}

Table 3. Regression estimates - socio-demographic

\begin{tabular}{|l|c|c|c|c|c|}
\hline \multirow{2}{*}{ Model } & \multicolumn{2}{|c|}{ Unstandardized Coefficients } & $\begin{array}{c}\text { Standardized } \\
\text { Coefficients }\end{array}$ & $\mathbf{t}$ & \multirow{2}{*}{ Sig. } \\
\cline { 2 - 4 } & $\mathrm{B}$ & Std. Error & Beta & & \\
\hline (Constant) & 2.587 & 1.233 & & 2.099 & .038 \\
\hline Age & -.062 & .123 & -.038 & -.505 & .614 \\
\hline Marital status & -.238 & .194 & -.098 & -1.224 & .223 \\
\hline Education & .132 & .083 & .129 & 1.590 & .114 \\
\hline Religion & -.236 & .284 & -.067 & -.830 & .408 \\
\hline Income & .350 & .130 & .220 & 2.684 & .008 \\
\hline House Type & .575 & .234 & .253 & 2.461 & .015 \\
\hline House Ownership & .320 & .144 & .180 & 2.216 & .015 \\
\hline Family Type & .399 & .229 & .152 & 1.741 & .084 \\
\hline Have Electricity & 1.033 & .22 & .454 & 4.658 & .000 \\
\hline How long living & -.435 & .180 & -.189 & -2.415 & .017 \\
\hline
\end{tabular}

The $\mathrm{R}^{2}$ of 0.303 indicate that the model is predicting the dependent variable (women empowerment) to about $30 \%$ only. The lower prediction rate is due to presence of interaction effects of other variables. The coefficient $b$ for one unit of increase in income the women empowerment level increases by 3.5 times, for one unit of increase in house type women empower- ment increases by 5.7 times, for one unit of increase in house ownership women empowerment increases by 3.2 times and one unit of increase in having electricity in the house increase women empowerment by 10.3 times while for one of increase in length of stay in the tribal village women empowerment decreases by $4.3 \%$ (Table 3 ). Socio-demographic factors income, house type, house 
ownership, having electricity positively influence empowerment levels of women and length of stay negatively influence empowerment levels of women in Kurumba tribes. Socio-demographic variables indicate that women in Kurumba tribe can gain empowerment among the communities with good income, quality housing, house ownership and access to electricity. The length of stay indicates that women staying within the tribal villages lack access to knowledge, education and employment as the tribal villages are located deep inside the forest. Living within the boundary of urban can help women to better reach for employment, schools, hospitals and information.

Socio-economic factors that influence women empowerment: To estimate the relationship and to investigate the influence of socio-economic factors a regression analysis is conducted. The model summary (Table 4 ) shows $\mathrm{R}^{2}$ of 0.604 which indicate that the model is explaining the dependent variable to about $60 \%$ and the model is significant with $\mathrm{f}$ value of 7.213 and $p$ value of 0.000 which is less than 0.05 (Table 5). The regression estimates measure the rate of change of one unit in independent variable to one unit of change in dependent value. The socio-economic factors get government aid $(b=0.417, p=0.010)$, knowledge on privileges $(b=0.653, p=0.000)$, health programs implemented $(b=0.609, p=0.004)$, living place is inherited $(b=0.501$, $\mathrm{p}=0.001)$, SHG useful $(\mathrm{b}=402, \mathrm{p}=0.000)$, discrimination in job $(b=0.147, p=0.050)$ has a significant positive relationship with women empowerment while dropped school for job $(b=-0.191, p=0.023)$, self employment improve the status $(b=-0.505, p=0.000)$, sell forest produce $(b=$ $-0.790, p=0.000)$, forest produces are useful $(b=-0.241, p$ $=0.002)$, difference in wages between men and women $(\mathrm{b}$ $=-0.257, \mathrm{p}=0.015)$ has significant negative relationship with women empowerment.

Table 4. Model summary - socio-economic factors

\begin{tabular}{|c|l|c|c|c|}
\hline \multicolumn{5}{|c|}{ Model Summary } \\
\hline Model & $\mathrm{R}$ & R Square & $\begin{array}{c}\text { Adjusted R } \\
\text { Square }\end{array}$ & $\begin{array}{c}\text { Std. Error of the } \\
\text { Estimate }\end{array}$ \\
\hline 1 & .777 & .604 & .520 & .789 \\
\hline
\end{tabular}

Table 5. ANOVA - socio-economic factors

\begin{tabular}{|r|l|r|r|r|r|r|}
\hline \multicolumn{7}{|c|}{ ANOVA } \\
\hline \multirow{2}{*}{1} & $\begin{array}{c}\text { Sum of } \\
\text { Squares }\end{array}$ & \multicolumn{1}{c|}{ df } & $\begin{array}{c}\text { Mean } \\
\text { Square }\end{array}$ & F & Sig. \\
\hline \multirow{2}{*}{1} & Regression & 116.608 & 12 & 4.485 & 7.213 & .000 \\
& Residual & 76.485 & 123 & .622 & & \\
& Total & 193.093 & 149 & & & \\
\hline
\end{tabular}

A positive relationship between independent variables and dependent variables indicates that a unit change in independent variable increases a unit in change in dependent variable while a negative relationship indicates that a unit increase in independent variable decreases a unit in dependent variable. The coefficient $b$ for one unit of increase in getting government aid increases women empowerment by 4.1 times, one unit of increase in knowledge on privileges increase women empowerment by 6.5 times, one unit of increase in health programs implemented increase women empowerment by 6.0 times, one unit of increase in living place is inherited increase women empowerment by 5.0 times, one unit of increase in SHG useful increases women empowerment by 4.0 times while one unit of increase in dropped from school for job decreases women empowerment by 1.9 times, one unit of increase in self employment improve status decreases women empowerment by 5.0 times, one unit of increase in sell forest produce decreases women empowerment by 7.9 times, one unit of increase in difference in wages between men and women decreases women empowerment by 2.5 times and one unit of increase in forest produce are useful decreases women empowerment by 2.4 times.

Socio-economic factors such as get government aid, knowledge on privileges, health programs implemented, living place is inherited and SHG useful positively influence empowerment levels of women in Kurumba tribes. Socio-economic factors such as dropped school for job, self employment improve the status, sell forest produce, forest produces are useful and difference in wages between men and women negatively influence empowerment levels of women in Kurumba tribes.

Table 6. Regression estimates - socio-economic factors

\begin{tabular}{|c|l|c|c|c|c|c|}
\hline \multirow{2}{*}{ Model } & \multicolumn{2}{|c|}{ Unstandardized Coefficients } & $\begin{array}{c}\text { Standardized } \\
\text { Coefficients }\end{array}$ & \multirow{2}{*}{$\mathbf{t}$} & \multirow{2}{*}{ Sig. } \\
\cline { 3 - 6 } & & $\mathbf{B}$ & Std. Error & Beta & & \\
\hline \multirow{3}{*}{1} & (Constant) & 2.587 & 1.233 & & 2.099 & .038 \\
\cline { 2 - 7 } & Dropped school For job & -.191 & .083 & -.181 & -2.308 & .023 \\
\cline { 2 - 7 } & Get Govt aid & .417 & .160 & .312 & 2.599 & .010 \\
\cline { 2 - 7 } & Knowledge on privileges & .653 & .137 & .487 & 4.776 & .000 \\
\hline
\end{tabular}




\begin{tabular}{|c|c|c|c|c|c|c|}
\hline & \multirow{2}{*}{ Model } & \multicolumn{2}{|c|}{ Unstandardized Coefficients } & \multirow{2}{*}{$\begin{array}{c}\begin{array}{c}\text { Standardized } \\
\text { Coefficients }\end{array} \\
\text { Beta }\end{array}$} & \multirow[t]{2}{*}{$\mathrm{t}$} & \multirow[t]{2}{*}{ Sig. } \\
\hline & & B & Std. Error & & & \\
\hline \multirow{9}{*}{1} & Health programs implemented & .609 & .210 & .229 & 2.896 & .004 \\
\hline & Place is inherited & .501 & .152 & .397 & 3.287 & .001 \\
\hline & Self employment improve & -.505 & .126 & -.475 & -4.016 & .000 \\
\hline & Sell forest products & -.790 & .207 & -.348 & -3.824 & .000 \\
\hline & Forest produce useful & -.241 & .078 & -.279 & -3.093 & .002 \\
\hline & Difference in Wages & -.257 & .105 & -.265 & -2.459 & .015 \\
\hline & SHG useful & .402 & .084 & .430 & 4.807 & .000 \\
\hline & Discrimination in job & .147 & .074 & .156 & 1.977 & .050 \\
\hline & Training benefits & .014 & .088 & .017 & .155 & .877 \\
\hline
\end{tabular}

Getting government aid, having knowledge on tribal privileges and finding SHG useful improve the women economic condition. If the living place is inherited, the status of ownership helps in utilizing land for agriculture, poultry and animal breeding purposes. Also better health programs implemented improve health condition and quality of life. Dropping school for job negatively influence empowerment levels as lack of education affect employment opportunity and skill development. Selling of forest produce and finding forest produce are useful in making money but it does not improve the economic condition as the forest produces are not sufficient to make enough money. When women are paid lower than men, Kurumba women cannot gain financial freedom and their contribution to the family remains lows.

\section{Conclusion}

The status of tribal women still remains low due lack of awareness on health, education, economic, culture, social, political and technology. It is important to study the factors that can positively influence the status of tribal women in the modern society. In this study the influence of socio-economic factors and socio-demographic factors on Kurumba women empowerment is studied. The findings of the study show that the socio-economic and socio-demographic factors positively influence women empowerments. The main drawback of tribal women is the access to knowledge within their villages and the lack of job opportunities to improve their economic conditions. Implementing skill development, entrepreneurial training on agriculture and farming, boosting with microfinance and participating more on SHG activities enable Kurumba women to gain knowledge and awareness. Efforts and support from
Government agencies and NGO should be continuously given to increase knowledge and awareness, which directly improves their socio-economic levels.

\section{References}

1. Krishnanunni CU, Mathews AJ. Role of MGNREGS in empowering tribal women of Attappady development block in Kerala state, India. Global Journal for Research Analysis. 2019; 8(4):149-51.

2. Nisha R, Asokhan M. Improving the participation of tribal women in developmental programmes. Journal of Extension Education. 2017; 28(4):5764-7. https://doi.org/10.26725/ JEE.2016.4.28.5764-5767

3. Mareeswaran P, Jansirani R, Asokhan M, Mani K, Duraisamy MR. Participation of tribal women in the developmental programmes for their livelihood security. Int J Curr Microbiol App Sci. 2017; 6(5):2181-5. https://doi.org/10.20546/ijcmas.2017.605.245

4. Gautam D. Empowerment of tribal women through skill development: The role of Self Help Groups. International Journal of Academic Research and Development. 2018. p. 34.

5. Manjunatha BR, Gangadhar MR. Socio-economic status of the Bettakuruba tribal women: A case study from the Chamarajanagara District, Karnataka. Antrocom: Online Journal of Anthropology. 2018; 14(1):129-37.

6. Acharya S. Empowering tribal women through entrepreneurship: A study of Self Help Groups in Gajapati District of Odisha. Indian Research Journal of Extension Education. 2018; 18(2):26-30.

7. Mondal T. Participation in SHG and the level of empowerment of the poor women: An empirical study between Pre-SHG and Post-SHG situations. IMPACT: International Journal of Research in Humanities, Arts and Literature. 2018; 6(01):239-50. 
8. Khanum R, Islam SM, Rahman S. Impact of entrepreneurship development on household income and expenditure: An empirical study on tribal women in Sylhet Region of Bangladesh. Bangladesh Journal of Agricultural Economics. 2018; 37(1-2). https://doi.org/10.22004/ag.econ.278757
9. Shamna A, Biswas P, Jha SK, Sarkar S, Kumar S. Tribal farm women's participation in agriculture and factors influencing it: Evidence from West Bengal, India. Journal of Agricultural Science and Technology. 2018; 20(5):911-22. 